\title{
Antimicrobial Activities of Microorganisms Obtained from the gut of Macrotermes michaelseni in Maseno, Kenya
}

\author{
Aswani Susan Ayitso $^{1 *}$, David Miruka Onyango ${ }^{1}$, Samuel Otieno Wagai ${ }^{2}$ \\ ${ }^{1}$ School of Biological and Physical Science, Maseno University.P.O. Box 333-40105, Maseno, Kenya. \\ ${ }^{2}$ Faculty of Science and Technology Engineering, Rongo University. P.O. Box 103-40404, Rongo, Kenya.
}

\section{ARTICLE INFO}

Article history:

Received on: 16/09/2015

Revised on: 08/11/2015

Accepted on: 22/11/2015

Available online: 19/12/2015

Key words:

Antibiotics, Macrotermes

michaeliseni, gut,

microhabitat, antibiotic

properties.

\begin{abstract}
The gut of termites is a major source of termicin and spinigerin antibiotics. The termite gut thus presents a novel habitat for searching new antibiotic producing isolates. The objective of this study was to investigate the microbial activities of microorganisms obtained from the gut of Macrotermes michaelseni. The Macrotermes michaelseni were collected from actively growing mound in Maseno University compound. Seventeen isolates were examined for their abilities to produce substances with antibiotic activities when grown in pure culture. All isolates formed measurable antibiotic activities against Escherichia coli, Staphylococcus aureas and Citrobacter freundii. The isolates did not form inhibition zones against Candida albicans, Shigella species and Salmonella paratyphi. The inhibition zones formed against Escherichia coli and Citrobacter freundii were significant in dilution while Staphylococcus aureas showed no significance in dilution. Two Factor Completely Randomized Design was applied. The analysis was done using MSTATC statistical package. Means from the measurements were separated using Turkey LSD and significance level tested at $\mathrm{p} \leq 0.05$. These results confirmed that the gut of Macrotermes michaelseni could be used as a source of natural products providing a new weapon against the problem of bacterial resistance to antibiotics.
\end{abstract}

\section{INTRODUCTION}

Little is known of the fungus cultivating termite's digestive processes and the microbial associates housed within the alimentary canal [1]. A few Actinomycete species have been isolated, but were not characterized for antibiotic production ability [2], yet increased antibiotic resistance by common pathogens means an increase for novel antibiotics. The termite gut thus presents a novel habitat for searching new antibiotic derivative producing strains. The wide spread use of microorganisms in the chemical and pharmaceutical industries has come about as a result of the recognition that it is often cheaper to use micro-organisms for synthesis of organic compounds such as antibiotics rather than to synthesize them chemically. Thousands of different antibiotics produced by Fungi, Actinomycetes or unicellular bacteria have been isolated and characterized. The secondary metabolites of the symbionts have not exhaustively been characterized yet they are of economic importance to human. This study was aimed at characterizing antibiotic producing isolates from Macrotermes michaelseni.

* Corresponding Author

Department of Biological Sciences, MasenoUniversity, P. O. Box 333 40105, Maseno, Kenya. Email : aswanisusan@yahoo.com, $\mathrm{Tel}+254-704866275$
Higher termites produce termicin and spinigerin antibiotics which are useful medically as well as for protection of plants from pathogenic fungi. Some antibiotic compounds isolated from termites have also been used for treating microbial infections such as sinusitis, bronchitis and skin infections [3]. Overuse of antibiotics, poor quality and counterfeit drugs with the wrong level of active therapeutic ingredients, has brought about adaptability of organisms that were earlier susceptible to various drugs to now become resistant and excessive use of antibiotics in agriculture and livestock to promote growth and prevent illnesses, have led to emergence of resistant microorganisms. Infections caused by resistant microorganisms often fail to respond to the standard treatment, resulting in prolonged illness, higher health care expenditures, and a greater risk of death [4]. When infections become resistant to first-line drugs, more expensive therapies must be used. A longer duration of illness and treatment, often in hospitals, increases health care costs as well as the economic burden on families and societies. The achievements of modern medicine are put at risk by multi-drug resistant microorganisms. Without effective antimicrobials for prevention and treatment of infections, the success of organ transplantation, cancer chemotherapy and major surgery would be compromised [5]. There is need to come up with cheaper, affordable, sources of new antimicrobials and hence the study of termites that could be handy in this operation. 


\section{MATERIALS AND METHODS}

\subsection{Study area}

The study was carried out in Maseno University. Maseno is a division in Kisumu County of Western Kenya. The sampling site is located along Kisumu - Busia highway 20 kilometers northwest of Kisumu town. Maseno lies at a latitude of $0^{\circ} 00^{\prime} 16.09^{\prime \prime}$ and longitude of $34^{\circ} 36^{\prime} 08.52^{\prime \prime}$ at altitude of $1500 \mathrm{~m}$. The mean annual rainfall ranges from $600-1200 \mathrm{~mm}$ per year and the average temperature is about $21.2^{\circ} \mathrm{C}$ with $20^{\circ} \mathrm{C}$ minimum and $23^{\circ} \mathrm{C}$ maximum daily temperatures. The vegetation is grassland with scattered bushes, dominated by Spothodea combanulata, Fucas benjamina, Cupresus funebris, Toona ciliata and herbs Bidens pilosa, Leocas calostachyus. The main economic activity is subsistence farming.

\subsection{Collection of Macrotemes species and preparation of homogenates}

The soldiers and workers were collected from an actively growing mound in Maseno Siriba campus. The Macrotermes species were sampled from the mound using a hoe. The samples were put in a plastic bag with mound soil, fungus combs and transported to the Zoology laboratory for identification. The Macrotermes species were degutted in the Botany lab using fine tipped forceps as previously described [6] then cultured on MM7 media.

\subsection{Preparation of culture media (MM7)}

The culture media used was MM7. This is a modification of MM5 [7] which is a defined mineral salt medium containing $\mathrm{NaCl}(1.7 \mathrm{~g}), \quad \mathrm{KCl} \quad(6.5 \mathrm{~g}) \quad \mathrm{MgCl}_{2} \cdot 6 \mathrm{H}_{2} \mathrm{O} \quad(0.50 \mathrm{~g})$, $\mathrm{CaCl}_{2} .2 \mathrm{H}_{2} \mathrm{O}(0.10 \mathrm{~g}), \mathrm{NH}_{4} \mathrm{Cl}(5.6 \mathrm{~g}), \mathrm{Na}_{2} \mathrm{SO}_{4}(1.0 \mathrm{~g})$ and $\mathrm{KH}_{2} \mathrm{PO}_{4}$ $(1.0 \mathrm{~g})$ dissolved in 1 litre of distilled water. The $\mathrm{pH}$ was adjusted to 7.0 with a buffer containing potassium dihydrogen phosphate as described by [7]. All solutions, cultures and media were prepared and maintained using aerobic techniques [8].

\subsection{Screening for antibiotic activities of the isolates}

Gram negative bacteria (Escherichia coli (ATCC 25922), Shigella species, Citrobacter freudi, salmonella paratyphi (ATCC 27785), gram positive bacteria Staphylococcus aureus (ATCC 25923) and fungus Candida abicans (ATCC7596) were collected from Kenya Medical Research Institute, Kisian laboratory and used as the screening organisms. The efficacy of various antibiotic agents against a range of gram positive and gram negative microbial strains was assessed through measurement of inhibition zones. Dilution susceptibility testing methods were used to determine the minimal concentration of antimicrobial to inhibit or kill the microorganism. Nutrient agar medium was prepared and sterilized. It was then poured into petri plates under aseptic conditions in a laminar air flow inoculated with one $\mathrm{ml}$ of bacterial suspension (test organisms). This standard inoculum contained 10 ${ }^{4}, 10^{-5}$ and $10^{-6}$ cells per $\mathrm{ml}$, and then the inoculation was distributed by a sterile cotton swab on the surface of the medium and left for five minutes in the lamina flow cabinet to dry. Fungal isolates were grown on potato dextrose agar. Artificially prepared sterilized disks (5 $\mathrm{mm}$ in diameter) were used. The disks were antiseptically picked using sterile forceps and then soaked in different dilutions of termite isolates two days old grown in basal salt medium. Damp wet disks were placed on the surface of medium seeded with test organisms. The plates were incubated for two days at $30^{\circ} \mathrm{C}$. All tests were done in triplicates. The diameter of inhibition zone was measured using a transparent ruler [9]. The test organisms were sub cultured every four months throughout the period of investigation to avoid the organisms dying due to lack of sufficient nutrients.

\section{RESULTS}

Table 1 presented mean length of inhibition zones in $\mathrm{mm}$ on Escherichia coli by isolates, Table 2 presented the Mean length of inhibition zones in $\mathrm{mm}$ on Citrobacter freundii by isolates, Table 3 presented Mean length of inhibition zones in $\mathrm{mm}$ on Staphylococcus aureas by isolates from Macrotermes michaelseni.

LSD 0.965 separates the means of isolates. The difference between two means that is greater or equal to the LSD is significantly different. LSD 1.67 separates the means of isolates and dilution and LSD 0.826 separates the means of dilutions.

LSD 1.248 separates the means of isolates. The difference between two means that is greater or equal to the LSD is significantly different. LSD 2.092 separates the means of isolates and dilution and LSD 0.205 separates the means of dilutions.

LSD 2.917 separates the means of isolates. The difference between two means that is greater or equal to the LSD is significantly different. LSD 4.669 separates the means of isolates and dilution and LSD 0.480 separates the means of dilutions.

Table 1: Mean length of inhibition zones in $\mathrm{mm}$ on Escherichia coli by isolates from Macrotermes michaelseni.

\begin{tabular}{|c|c|c|c|c|c|c|c|c|c|c|c|c|c|c|c|c|c|c|}
\hline \multirow{2}{*}{$\begin{array}{c}\text { Dilution } \\
\text { factor } \\
(\mathrm{ml})\end{array}$} & \multicolumn{17}{|c|}{ Isolates } & \multirow[t]{2}{*}{ Mean } \\
\hline & 1 & 2 & 3 & 4 & 5 & 6 & 7 & 8 & 9 & 10 & 11 & 12 & 13 & 14 & 15 & 16 & 17 & \\
\hline 0 & 7.00 & 9.00 & 0.00 & 0.00 & 19.33 & 7.00 & 8.00 & 0.00 & 7.33 & 14.33 & 0.00 & 0.00 & 8.33 & 6.00 & 8.67 & 7.00 & 6.00 & 6.35 \\
\hline 2 & 7.00 & 10.00 & 0.00 & 0.00 & 19.67 & 6.67 & 7.33 & 0.00 & 6.67 & 14.67 & 0.00 & 0.00 & 10.33 & 6.00 & 10.33 & 7.00 & 7.00 & 6.63 \\
\hline 4 & 7.00 & 10.00 & 0.00 & 0.00 & 19.67 & 7.67 & 7.00 & 0.00 & 14.67 & 15.67 & 0.00 & 0.00 & 9.67 & 6.00 & 7.67 & 7.00 & 7.00 & 7.00 \\
\hline mean & 7.00 & 9.67 & 0.00 & 0.00 & 19.56 & 7.11 & 7.44 & 0.00 & 9.56 & 14.89 & 0.00 & 0.00 & 9.44 & 6.00 & 8.89 & 7.00 & 6.67 & 6.60 \\
\hline LSD & & 0.965 & & & & & & & & & & & & & & & & 0.826 \\
\hline LSD AB & 1.67 & & & & & & & & & & & & & & & & & \\
\hline CV \% & 14.57 & & & & & & & & & & & & & & & & & \\
\hline
\end{tabular}


Table 2: Mean length of inhibition zones in mm on Citrobacter freundii by isolates from Macrotermes michaelseni.

\begin{tabular}{|c|c|c|c|c|c|c|c|c|c|c|c|c|c|c|c|c|c|c|}
\hline \multirow{2}{*}{$\begin{array}{l}\text { Dilution } \\
\text { factor(ml) }\end{array}$} & \multicolumn{17}{|c|}{ Isolates } & \multirow[t]{2}{*}{ Mean } \\
\hline & 1 & 2 & 3 & 4 & 5 & 6 & 7 & 8 & 9 & 10 & 11 & 12 & 13 & 14 & 15 & 16 & 17 & \\
\hline 0 & 6.67 & 7.00 & 2.33 & 0.00 & 4.67 & 7.67 & 2.67 & 0.00 & 7.00 & 6.00 & 0.00 & 0.00 & 7.00 & 4.00 & 6.00 & 0.00 & 6.00 & 3.94 \\
\hline 2 & 7.33 & 7.00 & 0.00 & 0.00 & 7.00 & 8.00 & 0.00 & 0.00 & 7.00 & 6.67 & 0.00 & 0.00 & 7.00 & 4.00 & 6.00 & 0.00 & 6.67 & 3.92 \\
\hline 4 & 7.67 & 7.00 & 0.00 & 0.00 & 7.00 & 8.00 & 0.00 & 0.00 & 7.00 & 7.00 & 0.00 & 0.00 & 7.00 & 6.00 & 6.00 & 0.00 & 6.67 & 4.08 \\
\hline Mean & 7.22 & 7.00 & 0.78 & 0.00 & 6.22 & 7.89 & 0.89 & 0.00 & 7.00 & 7.00 & 0.00 & 0.00 & 7.00 & 4.67 & 6.00 & 0.00 & 6.44 & 3.98 \\
\hline LSD & \multicolumn{17}{|c|}{1.248} & 0.205 \\
\hline LSD AB & \multicolumn{18}{|c|}{2.092} \\
\hline CV\% & \multicolumn{18}{|c|}{11.53} \\
\hline
\end{tabular}

$\mathrm{P} \leq 0.05$.

Table 3: Mean length of inhibition zones in mm on Staphylococcus aureas by isolates from Macrotermes michaelseni.

\begin{tabular}{|c|c|c|c|c|c|c|c|c|c|c|c|c|c|c|c|c|c|c|}
\hline \multirow{2}{*}{$\begin{array}{l}\text { Dilution } \\
\text { factor } \\
\text { (ml) }\end{array}$} & \multicolumn{17}{|c|}{ Isolates } & \multirow[t]{2}{*}{ Mean } \\
\hline & 1 & 2 & 3 & 4 & 5 & 6 & 7 & 8 & 9 & 10 & 11 & 12 & 13 & 14 & 15 & 16 & 17 & \\
\hline 0 & 10.00 & 9.00 & 8.00 & 0.00 & 14.33 & 10.00 & 0.00 & 0.00 & 6.67 & 16.00 & 0.00 & 0.00 & 7.33 & 7.67 & 6.67 & 0.00 & 10.33 & 6.24 \\
\hline 2 & 9.00 & 8.00 & 7.00 & 0.00 & 4.33 & 8.33. & 0.00 & 0.00 & 6.00 & 15.00 & 0.00 & 0.00 & 9.00 & 6.33 & 6.33 & 0.00 & 9.33 & 5.22 \\
\hline 4 & 8.67 & 7.00 & 4.00 & 5.33 & 5.67 & 5.00 & 0.00 & 2.33 & 10.00 & 6.00 & 0.00 & 0.00 & 8.33 & 6.00 & 6.00 & 0.00 & 9.33 & 4.86 \\
\hline Mean & 9.22 & 7.67 & 6.33 & 1.78 & 8.11 & 7.78 & 0.00 & 0.78 & 7.56 & 12.00 & 0.00 & 0.00 & 8.22 & 6.67 & 6.33 & 0.00 & 9.67 & 5.44 \\
\hline LSD & & 2.917 & & & & & & & & & & & & & & & & 0.480 \\
\hline LSD AB & 4.669 & & & & & & & & & & & & & & & & & \\
\hline CV \% & 23.93 & & & & & & & & & & & & & & & & & \\
\hline
\end{tabular}

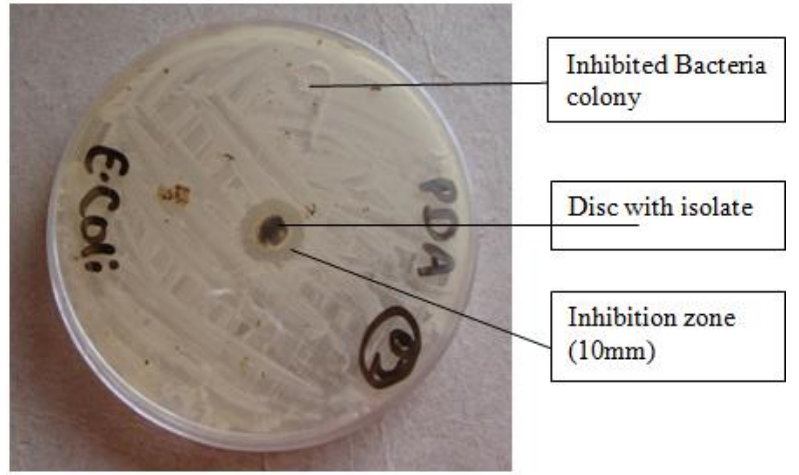

Isolate 2 in PDA medium showing zone of inhibition on E. coli at $0 \mathrm{ml}$ dilution.

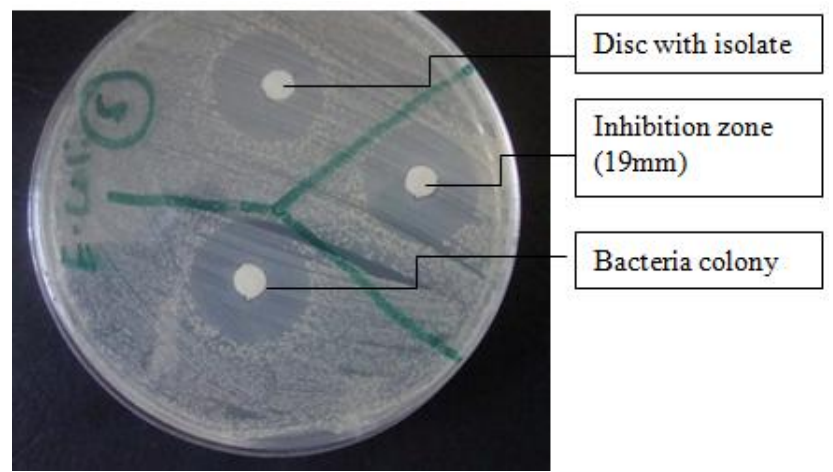

Isolate 5 in nutrient agar medium showing zone of inhibition on $E$. coli at $0 \mathrm{ml}$ dilution.

\section{DISCUSSION}

Seventeen isolates containing fourteen bacteria and three fungi were screened for antibiotic activity using pure test organisms. The isolates exhibited significant antimicrobial activity against $E$. coli, $S$. aureas and $C$. freundii; with no activity observed against Candida albicans, shigella species and Salmonella typhi. Inability of the antibacterial compound to inhibit both Grampositive and Gram-negative bacteria growth in the respective media set up could be due to variation in the cell wall permeability of bacteria to different drugs [5]. The antibiotics produced by the bacteria and fungi (isolates) were capable of killing or inhibit the growth of E. coli, S. aureas and C. freundii. This is because the biochemical evolution of antibiotic production took place in a situation where resistance to the effects of an antibiotic would confer a selective advantage on competitors [10]. Escherichia coli was observed to be the most susceptible test organism. Isolate five (5) exhibited the strong inhibitory effect on the growth of E. coli (19.5mm) and $S$. aureus (8mm).

The isolates had antibiotic properties exhibited by inhibition of bacteria species from growing in the medium where they were spread. This was an indication that those bacteria in the homogenate exhibit antimicrobial properties similar to those of Streptomyces. It has been established that one of the isolates from the termite hindgut is Streptomyces species [2] and it was shown to produce actinomycin. Actinomycins are members of chromopeptide lactone antibiotics; more than 30 native and many synthetic variants of these antibiotics are known. A novel cysteinerich peptide, named termicin, has been isolated from the fungusgrowing termite Pseudacanthotermes spiniger, a heterometabolous insect of the order of isoptera [3]. The activity spectrum of termicin is closer to that of the antifungal defensins than to that of the antibacterial defensins. In this study isolates 5(bacillus), 10 (streptococcus) and 13(bacillus) were able to exhibit broad spectrum anti microbial properties against E. coli and S. aureas, which is in contrast with activity shown by termicin because termicin show antifungal effect and weak antimicrobial activity against gram-positive strains while these isolates showed strong antibacterial effect on both gram-negative and gram-positive strains, which means that there is a possibility of these isolates producing different antibiotics. In this research inhibition of the microbe increased with dilution of the isolates, an indication that 
the microbe became more resistant when subjected to isolates of higher concentrations. The susceptibility of $E$. coli to isolates increased with dilution up to $2 \mathrm{ml}$ and susceptibility remained constant at dilution $4 \mathrm{ml}$. Other studies have shown that $E$. coli has recently represented highest prevalence of resistance against ampicillin and trimethoprim-sulfamethoxazole [11]. Surveillance data show that resistance in $E$. coli is consistently highest for antimicrobial agents that have been in use the longest time in human and veterinary medicine [12]. This could have been the reason why some isolates showed low and even no efficacy against the microbe since the microbes were of clinical origin where they could have been exposed to any of the antimicrobials thus making them resistant to the isolate.

This study has shown that $71 \%$ of the Macrotermes isolates have antibiotic activity against Citrobacter freudi. The inhibition of the microbe varied with dilution of the isolates. Significant inhibition zones were observed in isolates $1,2,5,6,9$, $10,13,15$, and 17 . The bacterium was resistant to isolates $4,8,11$, 12 and 16 as shown in table 2. In comparison to other studies $C$. freundii has recently been reported to express resistance to broadspectrum antibiotics including piperacillin, piperacillintazobactam, vancomycin and cephalosporins. Ceftriaxone-resistant Citrobacter freundii has been mostly isolated from patients with significant comorbidities including AIDS, peripheral vascular disease, and cerebrovascular disease [13]. Citrobacter freundii is known to contain in its chromosome a gene coding for cephalosporinase. This enzyme hydrolyses $-\mathrm{CO}-\mathrm{NH}-$ bond in the lactam ring of cephalosporins and cephamycis thus rendering the bacteria resistant to this type of antibiotics [14]. The resistance of the bacterium was demonstrated to five isolates but twelve isolates were able to produce antibiotic properties against it.

This research has established that $76.5 \%$ of the isolates have antibiotic activities against $S$. aureas. $S$. aureas was inhibited at higher concentration (0ml). Isolates I, 5, 6, 10, 13 and 17 showed antibacterial activity against S.aureas. The bacterium showed resistance to isolates 7,11,12 and 16 as shown in table 3 . However, other studies have shown that increase in use of vancomycin to treat infections caused by methicillin-resistant staphylococci, Clostridium difficile, and enterococcal infections preceded the emergence of vancomycin-resistant staphylococci. The altered cross-linking results from reduced amounts of Lglutamine that is available for amidation of D-glutamate in the pentapeptide bridge. Increased number of D-Ala-D-Ala residues that bind vancomycin, preventing the molecule from getting to its bacterial target [15]. Fluoroquinolone resistance develops as a result of spontaneous chromosomal mutations in the target of the antibiotic, topoisomerase IV or DNA gyrase, or by the induction of a multidrug efflux pump [16]. The recent increase of communityacquired MRSA infections reported in patients from different countries is associated with the detection of a unique SCCmec, type IV gene [17]. This element, smaller than the other elements, appears more genetically mobile and does not, at present, carry additional antimicrobial resistance genes, suggesting that it has been heterologously transferred more readily from other staphylococcal species [18]. Resistance to methicillin confers resistance to all $\beta$-lactam agents, including cephalosporins [19]. This finding confirms that a large percentage of isolates showed antibiotic activity against $S$. aureas. Potential antibiotic producers in termite gut were clearly shown in this study.

\section{CONCLUSION}

From the research it was observed that $72.8 \%$ of the isolates got from the gut of Macrotermes michaeliseni in Maseno have abilities to produce substances which exhibit antibiotic activities against E.coli, $S$. aureas and $C$. freundii but not with not against Candida albicans, shigella species and Salmonella typhi.

\section{ACKNOWLEDGEMENT}

The researchers are grateful to the Maseno University for allowing them to collect the Macrotermes michaeliseni from the University compound as well as extracting the isolates and screening for antibiotic activities in the University Botany laboratory. We appreciate the assistance of Mr. Solomon Manani in the extraction of isolates.

\section{REFERENCES}

1. Breznak JA. Ecology of prokaryotic microbes in the guts of woodand litter-feeding termites, T. Abe, D. E. Bignell, and M. Higashi [eds.], Termites: evolution, sociality, symbioses, ecology. Kluwer Academic Publishers. Dordrecht: The Netherlands; 2000.

2. Toru M, Junichi T, Tomoyuki N, Naoya S. Antibiotics production by an actinomycete isolated from the termite gut. Journal of Basic Microbiology. 2012; 52,731-735.

3. Lamberty M, Zachary D, Lanot R. Constitutive expression of a cystein-rich antifungal and a linear antibacterial peptide in a termite insect. Journal Biological Chemistry. 2001; 276: 4085- 4092.

4. World Health Organization. Diarrhoeal Diseases: Shigellosis. Initiative for Vaccine Research (IVR); 2013.

5. Struelens MC. The problem of resistance. In: Finch RG (ed) Antibiotic and chemotherapy: anti- infective agents and their use in therapy, 8th Ed. Elsevier Ltd. Printed in Great Britain. 2003; 28.

6. Schmitt-Wagner D, Friedrich MW, Wagner B, Brune A. Phylogenetic diversity, abundance, and axial distribution of bacteria in the intestinal tract of two soil-feeding termites (Cubitermes spp.). Applied Environmental Microbiology. 2003; 69: 6007-6017.

7. Miambi E, Guyot JP, Ampe F. Identification, isolation and quantification of representative bacteria from fermented cassava dough using an integrated approach of culture-dependent and cultureindependent methods. Introduction journal Food Microbiology. 2003; 82: 111-120.

8. Philip B, Schink B. Evidence of two oxidative reaction steps initiating anaerobic degradation of resorcinol (1, 3dihydroxybenzene) by denitrifying bacterium Azoarcus anaerobius. Journal Bacteriolology. 1998; 180: 3644-3649.

9. Dahot UM. Antimicrobial activities of small Protein of Moringa oleifera leaves. Journal Islamic Academic Science. 1998; 11: 1-11.

10. Wheat PF, Hastling JG, Spencer RC. Rapid antibiotic susceptibility tests on Enterobacteriaceae by ATP bioluminescence. Journal of medical microbiology. 1988; 25: 95-99.

11. Araújo SM, Mourão TC, Oliveira JL, Melo IF, Araújo CA, Araújo NA, Melo MC, Araújo SR, Daher EF. Antimicrobial resistance of uropathogens in women with acute uncomplicated cystitis from primary care settings. Introduction. Urology. Nephrogyl., Epublication; 2010. Available at: http://www.springerlink.com/ content/u9217t63117vg2 w5/ 
12. US Food and Drug Administration. National antimicrobial resistance monitoring system-enteric bacteria (NARMS): executive report. Rockville (MD); 2008

13. Kim PW, Harris AD, Roghmann MC, Morris JG, Strinivasan A, Perencevich EN. Epidemiological risk factors for isolation of ceftriaxone-resistant versus - susceptible citrobacter freundii in hospitalized patients. Antimicrobial Agents Chemotherapy. 2003; 47 (9): 2882-2887.

14. Nada T, Baba H, Kawamura K, Ohkura T, Torii K, Ohta M. A small outbreak of third generation cephem-resistant Citrobacter freundii infection on a surgical ward. Japan Journal Infectious Disease. 2004; 57(4): 181-182.

15. Hooper DC. Fluoroquinolone resistance among Gram-positive cocci. 2002; 2:530-538

16. Sieradzki K, Pinho MG, Tomasz A. Inactivated pbp4 in highly glycopeptide-resistant laboratory mutants of Staphylococcus aureus. Journal Biological Chemistry. 1999; 274:18942-18946.

17. Ma XX. Novel type of staphylococcal cassette chromosome mec identified in community-acquired methicillin-resistant Staphylococcus aureus strains. Antimicrobiol Agents Chemotherapy. 2002; 46: 1147-1152.
18. Okuma K. Dissemination of new methicillin-resistant Staphylococcus aureus clones in the community. Journal Clinical Microbiology. 2002; 40:4289-4294.

19. Lim D, Strynadka NC. Structural basis for the beta lactam resistance of PBP2a from methicillin-resistant Staphylococcus aureus. Natural Structural Biology. 2002; 9:870-876.

\section{How to cite this article:}

Ayitso AS, Onyango DM and Wagai SO. Antimicrobial Activities of Microorganisms Obtained from the gut of Macrotermes Michaelseni in Maseno, Kenya. J App Biol Biotech, 2015; 3 (06): 048-052. DOI: 10.7324/JABB.2015.3608 